\section{What is already known on this topic}

The practice of covert drug administration in food and beverages is well known in residential and nursing homes, but no prevalence rates exist

No information is available on which patients are particularly subjected to covert administration or on the procedures for documenting the practice

\section{What this study adds}

In Norway, $11 \%$ of patients in regular nursing home units and $17 \%$ of patients in special care units for dementia were covertly administered drugs at least once, and in $95 \%$ the practice was routine

Patients with severe cognitive impairment, reduced function in activities of daily living, or aggressive behaviour were more often subjected to covert administration

The practice of covert drug administration was poorly documented in the patients' records

units would have been subjected to covert administration, because the staff in a special care unit are usually more highly trained and aware of the patients' needs, but the reverse was true. The most likely explanation is that the proportion of patients with a severe degree of dementia and behavioural problems is extremely high in special care units. Hiding the sedative drugs in food and beverages may in many cases be the only way of administering the drugs, because of the noncooperation of patients who may lack the capacity to understand and give consent to drug treatment.

\section{Who takes the decision?}

We are concerned that the physician responsible for medical treatment in nursing homes is not involved in all cases in which it is decided to give drugs covertly. We believe that such involvement would reduce the frequency of the practice, or at least that the practice would be better documented. A Swedish study showed that the quality assurance of drug administration was positively associated with the quality of the communication between the physician and the nurses, and was higher in nursing homes where discussions about drug treatment took place in the multidisciplinary team. ${ }^{15}$ Nygaard et al have reported that in nursing homes with a full time physician the use of antipsychotic drugs is lower than in nursing homes where a physician works part time. ${ }^{16}$ Even though these two studies did not include covert administration, the importance of an interested physician, cooperating with other health personnel in the nursing home to reduce the use of covert administration, might be substantial.

\section{Conclusion}

The practice of mixing drugs in patients' food and beverages is common in Norwegian nursing homes but is poorly documented in the patients' records. The procedure for the decision to hide drugs seems to be arbitrary.

\section{Contributors: See bmj.com}

Funding: The research is supported by grants from the Norwegian Ministry of Health and Social Affairs (project number 16124); the Norwegian Foundation for Health and Rehabilitation through the Norwegian Health Association (project number 2001/2/0077); the Lions Club Norway; and the Norwegian Centre for Dementia Research.

Competing interests: None declared.

Ethical approval: The Regional Committee for Medical Research, the Data Inspectorate, and Department of Health approved the study.

1 Hughes CM, Lapane KL, Mor V. Influence of facility characteristics on use of antipsychotic medications in nursing homes. Med Care 2000;38:1164-73.

2 Lindesay J, Matthews R, Jagger C. Factors associated with antipsychotic drug use in residential care: changes between 1990 and 1997. Int J Geriatr Psychiatry 2003;18:511-9.

3 Phillips CD, Spry KM, Sloane PD, Hawes C. Use of physical restraints and psychotropic medications in Alzheimer special care units in nursing homes. Am J Public Health 2000;90:92-6.

4 Ruths S, Straand J, Nygaard HA. Psychotropic drug use in nursing homes-diagnostic indications and variations between institutions. Eur J Clin Pharmacol 2001;57:523-8.

5 Sorensen L, Foldspang A, Gulmann NC, Munk-Jorgensen P. Determinants for the use of psychotropics among nursing home residents. Int $J$ Geriatr Psychiatry 2001;16:147-54

6 Kow JV, Hogan DB. Use of physical and chemical restraints in medical teaching units. CMAJ 2000;162:339-40.

7 Middleton H, Keene RG, Johnson C, Elkins AD, Lee AE. Physical and pharmacologic restraints in long-term care facilities. J Gerontol Nurs 1999;25:26-33.

8 Thurmond JA. Nurses' perceptions of chemical restraint use in long-term care. Appl Nurs Res 1999;12:159-62.

9 Treloar A, Beats B, Philpot M. A pill in the sandwich: covert medication in food and drink.JR Soc Med 2000;93:408-11.

10 Blythe J. Study questions ethics of covert medication. BMJ 2000;321:402.

11 Honkanen L. Point-counterpoint: is it ethical to give drugs covertly to people with dementia? No: covert medication is paternalistic. West J Med 2001;174:229.

2 Ramsay S. UK nurses receive guidance on covert medication of patients. Lancet 2001;358:900.

13 Kirkevold Ø, Laake K, Engedal K. Use of constraints and surveillance in Norwegian wards for the elderly. Int J Geriatr Psychiatry 2003;18:491-7.

14 Hox J. Multilevel analysis: techniques and applications. Mahwah, NJ Hox J. Multilevel analysis: techniques

15 Schmidt IK, Svarstad BL. Nurse-physician communication and quality of Schmidt IK, Svarstad BL. Nurse-physician communication and qua
drug use in Swedish nursing homes. Soc Sci Med 2002;54:1767-77.

16 Nygaard HA, Brudvik E, Juvik OB, Pedersen WE, Rotevatn TS, Vollset Å Consumption of psychotropic drugs in nursing home residents: a prospective study in patients permanently admitted to a nursing home. Int J Geriatr Psychiatry 1994;9:387-91.

(Accepted 22 September 2004)

doi $10.1136 / \mathrm{bmj} .38268 .579097 .55$

\title{
What's the point
}

Points, points? I am running to time and thinking, "Can I get some points in this consultation?" After all, in the new world of general practice where points make prizes, dealing with the problem is no longer enough. The new UK GP contract has changed the interaction with patients by quantifying (and rewarding) certain clinical activities, particularly data collection.

My eyes quickly scan the prevention screen of the computer and see that we have no smoking status on this man.
By this stage he has put his coat back on and is nearly at the door.

"Do you smoke?" I ask quickly.

He looks a bit puzzled and fumbles for his cigarettes: "Yes. Do you want one?"

Melvyn Jones lecturer in general practice, department of primary care and population sciences, Royal Free and University College Medical School,London (m.jones@pcps.ucl.ac.uk) 